\title{
Glutamate excitotoxicity in glaucoma: truth or fiction?
}

Eye (2005) 19, 369-370. doi:10.1038/sj.eye.6701623

In the journal this month, Kwon et al report that vitreous and retinal glutamate levels are not raised in a primate model of central retinal artery occlusion. Why is this negative result important?

In recent years, glutamate 'excitotoxicity' has been proposed as a mechanism by which retinal ganglion cells die in glaucoma. ${ }^{1}$ If true, this could lead to exciting new treatments for glaucoma. Perhaps an entirely novel portfolio of glutamate antagonist drugs could be developed and provide an additional treatment armamentarium rather than simply treating intraocular pressure. However, if the basic hypothesis is false then valuable research funds should be directed elsewhere.

Unfortunately, one of the principal researchers involved in developing the glutamate retinal toxicity hypothesis, has been found guilty of scientific fraud. ${ }^{2,3}$ Therefore, in the context of this new negative study it is important to re-evaluate the evidence for and against glutamate being causal in the development of glaucoma.

Glutamate is an essential amino acid. It is the main excitatory neurotransmitter in the mammalian central nervous system (CNS) and mediates neurotransmission across most excitatory synapses. ${ }^{4}$ It binds to three receptors, with glutamate toxicity apparently being primarily mediated via glutamate binding to the $N$-methyl-D-aspartate (NMDA) glutamate receptor. ${ }^{4-6}$ NMDA receptors are abundant, ubiquitously distributed throughout the brain, fundamental to excitatory neurotransmission, and critical for normal function. ${ }^{4}$ Excess glutamate chronically over stimulates NMDA receptors with subsequent release of excess intracellular calcium leading to neuronal cell death. ${ }^{5,7-9}$ This then causes 'excitotoxicity',
AJ Lotery

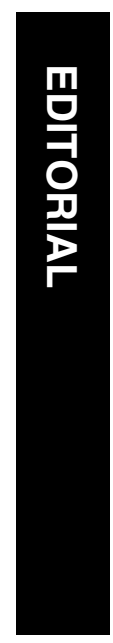

that is, toxicity due to excess stimulation by an excitatory amino acid.

CNS disorders in which glutamate-induced excitotoxicity are implicated include cerebral ischaemia, in stroke or brain trauma; neurodegenerative disorders such as Parkinson's and Huntington's diseases and disorders such as epilepsy and neuropathic pain, in which there is overactivity of excitatory pathways. ${ }^{4,7}$ The rationale for the acute treatment of brain ischaemia with NMDA antagonists is strong ${ }^{10}$ as nonselective NMDA antagonists are the most consistently neuroprotective agents in animal models with stroke. Nevertheless, clinical trials in stroke and traumatic brain injury with NMDA antagonists have so far been disappointing. ${ }^{10-12}$

In the mammalian eye, the toxic effects of glutamate have been known since $1957 .{ }^{13}$ Investigators trying to block retinal degenerations found that subcutaneous glutamate injections in mice led to severe degeneration of the inner retinal layers especially the ganglion cell layer. Intraocular glutamate can also cause excavation of the optic nerve in neonatal mice injected with intraocular glutamate. ${ }^{14}$ Direct toxicity to retinal ganglion cells has also been demonstrated. A single intravitreal injection of $20 \mathrm{nM}$ of NMDA killed $70 \%$ of retinal ganglion cells in the adult rat retina. $^{15}$

These findings support the hypothesis that increased glutamate synthesis or decreased glutamate clearance results in excitotoxic damage to ganglion cells and contributes to the pathophysiology of glaucoma. However, if this is true, elevated glutamate levels should be detected in both the eyes of humans with glaucoma and animal models.

This is exactly what Dr Evan Dreyer demonstrated in what is considered the seminal paper in this field. ${ }^{16}$ He reported strikingly elevated vitreal glutamate
Southampton General Hospital

Human Genetics Divison University of Southampton Tremona Road Southampton S016 6YD UK

Correspondence: AJ Lotery Tel: +4402380794590

Fax: +4402380794120

E-mail: a.j.lotery@ soton.ac.uk 
concentrations in all forms of glaucoma to concentrations twice that of control eyes in patients, sixto eight- fold in monkeys with experimental glaucoma ${ }^{16}$ and four-fold in dogs with naturally occurring glaucoma. ${ }^{17}$ Based on these reports of elevated vitreal glutamate, glutamate excitotoxicity has been proposed to contribute to the ganglion cell death which is fundamental to glaucoma. ${ }^{1}$

However, neither a larger study of vitreal glutamate concentration in monkeys with experimental glaucoma ${ }^{18}$ nor a further study of vitreal glutamate levels in humans ${ }^{19}$ could replicate Dr Dreyer's findings. ${ }^{16}$ What is even more surprising are the results of the current study by Kwon et al. Elevated vitreal glutamate levels were not found in a primate model of central retinal artery occlusion. If the ischaemic death of a small number of retinal ganglion cells in glaucoma truly produces elevated vitreal glutamate levels, then this model of profound inner retinal ischaemia with the associated death of a million ganglion cells should produce grossly elevated vitreal glutamate levels. It did not.

How can we reconcile these disparate findings? Of note, Dr Dreyer has admitted to falsifying experimental results to support the hypothesis that elevated levels of glutamate play a role in Meniere's disease. $^{2,3}$ A subsequent review of Dr Dreyer's work noted that the primary high-performance liquid chromatography data for his prominent article on elevated intravitreal glutamate levels ${ }^{16}$ could not be found. ${ }^{3}$ It was these same data that were falsified in his study of Meniere's disease. In January 2000, the Office of Research Integrity (ORI) of the National Institutes of Health became sufficiently concerned about this paper ${ }^{16}$ to notify both the National Institute of Health and the Food and Drug Administration (FDA). The FDA was informed because ORI officials believed that the paper had been used in support of a clinical trial of an NMDA antagonist drug called memantine being undertaken by Allergan of Irvine, California. $^{3}$

In light of these concerns, the negative result reported by Kwon et al is important. Authors of negative studies often have great difficulty getting their work published. In some cases, such studies may be more important to the scientific community than positive studies. At the very least, this study significantly adds to the body of evidence that there is no elevation of vitreal glutamate in patients with glaucoma ${ }^{19}$ or in animal models of glaucoma. ${ }^{18}$ It suggests the need to re-evaluate carefully the potential role of glutamate excitotoxicity in glaucoma. This is vital so we can tell our patients what is truth and what is fiction and direct our research efforts appropriately.

\section{References}

1 Vorwerk CK, Gorla MS, Dreyer EB. An experimental basis for implicating excitotoxicity in glaucomatous optic neuropathy. Surv Ophthalmol 1999; 43 (Suppl 1): S142-S150.

2 Department of Health Human Services. Findings of scientific misconduct 2000. http://grants.nih.gov/grants/ guide/notice-files/NOT-OD-01-006.html

3 Dalton R. Private investigations. Nature 2001; 411: 129-130.

4 Kemp JA, McKernan RM. NMDA receptor pathways as drug targets. Nat Neurosci 2002; 5 (Suppl): 1039-1042.

5 Sucher NJ, Wong LA, Lipton SA. Redox modulation of NMDA receptor-mediated Ca2 + flux in mammalian central neurons. Neuroreport 1990; 1: 29-32.

6 Sucher NJ, Aizenman E, Lipton SA. N-methyl-D-aspartate antagonists prevent kainate neurotoxicity in rat retinal ganglion cells in vitro. J Neurosci 1991; 11: 966-971.

7 Choi DW. Glutamate neurotoxicity and diseases of the nervous system. Neuron 1988; 1: 623-634.

8 Hahn JS, Aizenman E, Lipton SA. Central mammalian neurons normally resistant to glutamate toxicity are made sensitive by elevated extracellular Ca2 + : toxicity is blocked by the N-methyl-D-aspartate antagonist MK-801. Proc Natl Acad Sci USA 1988; 85: 6556-6560.

9 Sucher NJ, Lei SZ, Lipton SA. Calcium channel antagonists attenuate NMDA receptor-mediated neurotoxicity of retinal ganglion cells in culture. Brain Res 1991; 551: 297-302.

10 Kemp JA, Kew JNC, Gill R, Jones P, Monyer H. Handbook of Experimental Pharmacology. Handbook of Exp Pharmacol 1999; 141: 495-527.

11 Lees KR, Asplund K, Carolei A, Davis SM, Diener HG Kaste $\mathrm{M}$ et al. Glycine antagonist (gavestinel) in neuroprotection (GAIN International) in patients with acute stroke: a randomised controlled trial. GAIN International Investigators. Lancet 2000; 355: 1949-1954.

12 Sacco RL, DeRosa JT, Haley EC Jr, Levin B, Ordronneau P, Phillips SJ et al. Glycine antagonist in neuroprotection for patients with acute stroke: GAIN Americas: a randomized controlled trial. JAMA 2001; 285: 1719-1728.

13 Lucas DR, Newhouse JP. The toxic effect of sodium L-glutamate on the inner layers of the retina. Ama Arch Opthalmol 1957; 58: 193-201.

14 Azuma N, Kawamura M, Kohsaka S. Morphological and immunohistochemical studies on degenerative changes of the retina and the optic nerve in neonatal rats injected with monosodium-L-glutamate. Nippon Ganka Gakkai Zasshi 1989; 93: 72-79.

15 Siliprandi R, Canella R, Carmignoto G, Schiavo N, Zanellato A, Zanoni R et al. $N$-methyl-D-aspartate-induced neurotoxicity in the adult rat retina. Vis Neurosci 1992; 8: 567-573.

16 Dreyer EB, Zurakowski D, Schumer RA, Podos SM, Lipton SA. Elevated glutamate levels in the vitreous body of humans and monkeys with glaucoma. Arch Ophthalmol 1996; 114: 299-305.

17 Brooks DE, Garcia GA, Dreyer EB, Zurakowski D, FrancoBourland RE. Vitreous body glutamate concentration in dogs with glaucoma. Am J Vet Res 1997; 58: 864-867.

18 Carter-Dawson L, Crawford ML, Harwerth RS, Smith EL 3rd, Feldman R, Shen FF et al. Vitreal glutamate concentration in monkeys with experimental glaucoma. Invest Ophthalmol Vis Sci 2002; 43: 2633-2637.

19 Honkanen RA, Baruah S, Zimmerman MB, Khanna CL, Weaver YK, Narkiewicz J et al. Vitreous amino acid concentrations in patients with glaucoma undergoing vitrectomy. Arch Ophthalmol 2003; 121: 183-188. 